\title{
Efficacy of second-look endoscopy in preventing delayed bleeding after endoscopic submucosal dissection of early gastric cancer
}

\author{
ZHIGUO GUO ${ }^{1}$, LIN MIAO ${ }^{2}$, LIJUAN CHEN ${ }^{3}$, HONGSHENG HAO $^{4}$ and YI XIN $^{1}$ \\ ${ }^{1}$ Department of Gastroenterology, Suzhou Municipal Hospital, Suzhou, Anhui 234000; ${ }^{2}$ Medical Center for Digestive Diseases, \\ The Second Affiliated Hospital of Nanjing Medical University, Nanjing, Jiangsu 210011; ${ }^{3}$ Department of Gastroenterology, \\ Central Hospital of Shandong Energy Zaozhuang Mining Group, Zaozhuang, Shandong 277100; \\ ${ }^{4}$ Department of Gastroenterology, Qilu Hospital of Shandong University, Jinan, Shandong 250012, P.R. China
}

Received January 11, 2018; Accepted August 2, 2018

DOI: $10.3892 /$ etm.2018.6729

\begin{abstract}
The present study aimed to evaluate whether second-look endoscopy (SLE) is able to prevent delayed bleeding after endoscopic submucosal dissection (ESD) of gastric carcinoma and to identify which types of lesion require SLE. ESD of gastric cancer at the early stage was performed on 210 patients between October 2014 and September 2016. Mucosal damage-associated bleeding within $24 \mathrm{~h}$ after ESD was considered as delayed bleeding. The association of the characteristics of patients and lesions, as well as surgical factors, with the incidence of bleeding as a measure of outcome was analyzed. A total of 110 patients with melena and/or hematemesis underwent SLE on the second day following gastric ESD. Within the entire cohort $(n=210)$, late delayed bleeding (LDB) was defined as hematemesis or melena occurring following second-look endoscopy. Early delayed bleeding (EDB) was defined as hematemesis or melena occurring from the end of ESD to second-look endoscopy, or as active or possible bleeding at the time of the second-look endoscopy was reported in $17(8.1 \%)$ and 20 patients(9.5\%), respectively. The median interval between late delayed bleeding and ESD was one day (range, 1-10 days). The incidence of late delayed bleeding was significantly decreased in the SLE group compared with that in the non-SLE group (4.5 vs. $12 \%$, $\mathrm{P}=0.028)$. Multivariate analyses revealed that ulcer, flat gross type, lesion diameter $(>2 \mathrm{~cm})$, the resected tumor size of $>40 \mathrm{~mm}$ and Helicobacter pylori infection were independently
\end{abstract}

Correspondence to: Dr Lin Miao, Medical Center for Digestive Diseases, The Second Affiliated Hospital of Nanjing Medical University, 121 Jiangjiayuan, Nanjing, Jiangsu 210011, P.R. China E-mail: miaofrest@163.com

Abbreviations: EGC, early gastric cancer; EMR, endoscopic mucosal resection; ESD, endoscopic submucosal dissection; SLE, second-look endoscopy

Key words: early gastric cancer, endoscopic submucosal dissection, second-look endoscopy, delayed bleeding associated with late delayed bleeding after ESD, while flat gross type, ulcer, the resected tumor size of $>40 \mathrm{~mm}$ and artificial ulcer diameter $>3 \mathrm{~cm}$ were independently associated with early delayed bleeding. Thus, the data of the present study indicates that second-look endoscopy following gastric ESD may be useful in preventing post-ESD delayed bleeding and should be performed on the second day.

\section{Introduction}

Gastric carcinoma usually arises from the gastric mucosa (1). In the US, the incidence of gastric carcinoma is 8.7-17.2 per 100,000 men and 9.7-43.1 per 100,000 women (2). In China, the incidence of gastric carcinoma is high, with the age-standardized incidence being 37.1 per 100,000 men and 17.4 per 100,000 women (3). This high incidence is probably due to the high prevalence of Helicobacter pylori infection in China, which is a definite gastric carcinogen according to the World Health Organization $(3,4)$.

Endoscopic mucosal resection (EMR) and endoscopic submucosal dissection (ESD) are widely used to treat early gastric cancer (EGC) and gastric adenocarcinoma (5). In patients with EGC, the outcome of endoscopic procedures with regard to survival is the same as that of gastrectomy, but endoscopic procedures are associated with a shorter hospital stay and decreased risk of post-operative morbidity (6). Furthermore, ESD is significantly better than EMR for removal of large lesions (7-9).

One concern regarding ESD is the generation of artificial ulcers, and studies describe delayed bleeding after ESD as life-threatening with an incidence of $~ 5 \%(10,11)$. Endoscopic hemostasis is effective during emergency endoscopy. Therefore, it is necessary to determine the nature of delayed bleeding and administer appropriate treatments. Previous studies have suggested that the tumor site (middle and lower third of the stomach), tumor size and ulcer formation are independent risk factors for delayed bleeding (12-14), but there is no consensus.

To further reduce the bleeding rate after ESD, numerous hospitals in Europe and the US routinely perform second-look endoscopy (SLE) to prevent delayed bleeding (15). The major purpose of SLE after ESD is to inspect the non-bleeding visible 
blood vessels of the mucosal defect that had bled recently or may eventually bleed $(11,16)$. When a bleeding or non-bleeding visible blood vessel is identified by SLE, preventive hemostasis should be performed; hemostatic clipping or thermocoagulation may be applied. However, it is controversial whether SLE is able to prevent delayed bleeding. A multicenter, prospective, randomized controlled non-inferiority trial did not recommend SLE to prevent delayed bleeding after gastric ESD (17), as supported by certain other previous studies (16,18-20).

Therefore, the present study aimed to evaluate whether SLE is able to prevent delayed bleeding, to assess the clinical and pathological characteristics of patients with delayed bleeding, and determine which specific lesions may require SLE. The results of the present study may lead to the establishment of improved guidelines to manage patients with EGC.

\section{Materials and methods}

Study design and patients. The present study was a retrospective analysis of a prospective database of patients who were histologically diagnosed with EGC and treated with ESD at the Center for Digestive Medicine (key clinical entity of Jiangsu Province) of the Second Affiliated Hospital of Nanjing Medical University (Nanjing, China) and at the Department of Gastroenterology (key clinical entity of the Ministry of Health, China) of the Qilu Hospital of Shandong University (Jinan, China) between October 2014 and September 2016.

According to the guidelines of the Japan Gastroenterological Endoscopy Society and the Japanese Gastric Cancer Association (7), the indications for ESD were lymph node-negative EGC, including the following: i) Differentiated intramucosal carcinoma with a diameter of $\geq 2 \mathrm{~cm}$ without ulcer; ii) differentiated intramucosal carcinoma with a diameter of $<3 \mathrm{~cm}$ and ulcer; and iii) undifferentiated intramucosal carcinoma with a diameter of $<2 \mathrm{~cm}$ without ulcer. The diagnosis was made based on lesions identified on endoscopy, chromoendoscopic biopsy or endoscopic ultrasonography. The exclusion criteria were as follows: i) Digestive tract perforation or ii) surgical specimens exhibiting submucosal invasion of $\geq 500 \mu \mathrm{m}$. The 3 treating gastroenterologists were all senior resident physicians or deputy chief physicians, and all had a working experience in ESD of $>3$ years and had performed $>100$ ESDs. All operators had received training in narrow-band imaging for detection of abnormal tumor vessels.

Of the 217 gastric neoplasm patients, 3 were excluded due to perforation during ESD, and 4 were excluded as an additional surgery was required for submucosal invasion. Finally, 210 patients were randomly divided into 2 groups: The non-SLE group $(n=100)$ and the SLE group $(n=110)$. Of the 210 patients, 172 were diagnosed with gastric high-grade intraepithelial neoplasia and 38 were diagnosed with gastric low-grade intraepithelial neoplasia. The present study was approved by the ethics committee of the Second Affiliated Hospital of Nanjing Medical University and Qilu Hospital of Shandong University. All patients provided written informed consent for inclusion in the database.

ESD strategy. All patients were required to provide written informed consent prior to treatment. ESD was performed as previously described (21). The patients fasted from the morning on the operation day and underwent surgery under conscious sedation. Argon plasma coagulation (PSD-60; Olympus, Tokyo, Japan) was used for marking, and the marking points were $5 \mathrm{~mm}$ away from the tumor edge. A submucosal injection of 1:10,000 epinephrine $(0.01 \mathrm{mg} / \mathrm{ml})+$ saline solution equal to a total of 10.0-15.0 ml was performed around the lesion. The mucosa was cut $5 \mathrm{~mm}$ away from the outer edge of the marking. After mucosal incision, the lesion was dissected using an IT knife (KD-612L or Dual knife (KD-650Q; both Olympus). Electrocoagulation of all visible vessels on the ulcer surface was performed using hot biopsy forceps (FD-410LR; Olympus). Sodium hyaluronate was used when saline: Epinephrine $(1: 100,000)$ was not able to completely lift the tumor. After the lesion was dissected from the stomach, conventional electrocoagulation of non-bleeding visible vessels and infiltration were performed using hot biopsy forceps.

SLE or emergency endoscopy. SLE was performed on the second day after ESD. Delayed bleeding was characterized by the presence of melena, hematochezia or hematemesis within $24 \mathrm{~h}$ after ESD, and mucosal defects and bleeding were observed during emergency endoscopy (22). Delayed bleeding was classified as early (hematemesis or melena occurring in the time interval between ESD and SLE or active or possible bleeding at the time of the SLE) and late (hematemesis, hematochezia or melena occurring after SLE) delayed bleeding. If there was significant bleeding, hemostasis of the bleeding points or non-bleeding visible vessels was performed under emergency endoscopy, mainly including hemostatic clamps or thermocoagulation. Patients who had hematochezia, hematemesis or hypotension and met the criteria were given component blood transfusion. After ESD, continuous intravenous esomeprazole administration (40 mg/day) was performed for 2 days. On the third day, administration was changed to oral esomeprazole $(20 \mathrm{mg}$ twice per day). Most patients started eating food after SLE. The patients were discharged from the hospital at 6 days after surgery unless bleeding complications were noted. If hematochezia or hematemesis occurred after discharge, the patients were required to contact their physicians. When perforation or delayed bleeding occurred, food intake and discharge plans were changed depending on the patient's condition. The patients were routinely followed up for 60 days in the first, second, fourth and eighth week after discharge. The results of routine blood tests and fecal occult blood test were recorded. The resection was considered curative when the lesion was resected en bloc, was $<2 \mathrm{~cm}$ in diameter, was predominantly of the differentiated type, demonstrated macroscopically intramucosal differentiated carcinomas (pT1a), was absent of ulcers (UL-), lymphatic invasion (ly-) and venous invasion (v-) (7). Expanded criteria for curative resection were en bloc resection of the lesion and a diameter of $\geq 2 \mathrm{~cm}$, a predominantly differentiated type, pT1a and UL(-); a diameter of $<3 \mathrm{~cm}$, a predominantly differentiated type, pT1a and $\mathrm{UL}(+)$; a diameter of $<2 \mathrm{~cm}$, a predominantly undifferentiated type, pT1a and UL(-); or a diameter of $<3 \mathrm{~cm}$, a predominantly differentiated type, $\mathrm{pT} 1 \mathrm{~b}$ (SM1), ly(-) and v(-); and negative surgical margins applied to all of the above (7). 


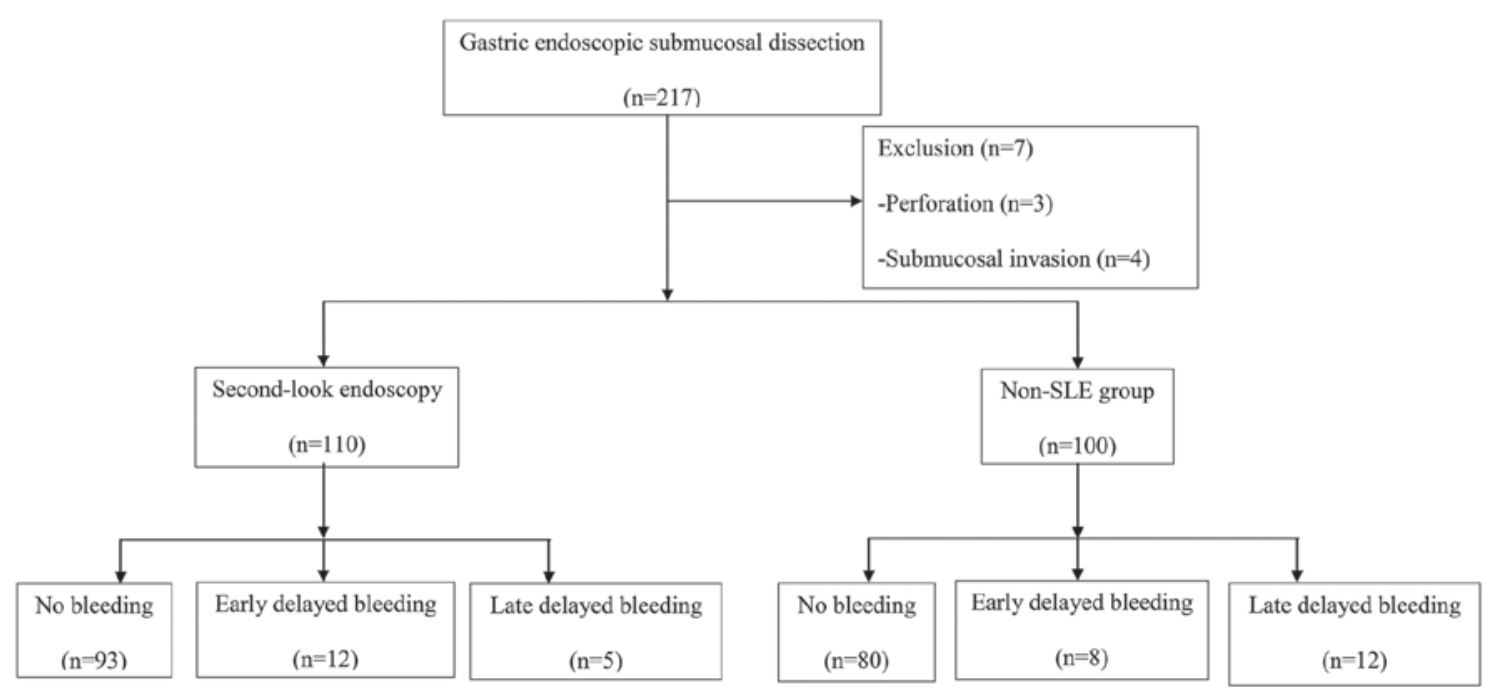

Figure 1. Flow chart of patients in the present study. SLE, second-look endoscopy.

Data collection. The following information was recorded: Age, sex, comorbidities (hypertension, heart disease, type 2 diabetes and acute cerebrovascular disease), use of anti-coagulants or anti-platelet drugs (patient-associated factors), $H$. pylori infection, longitudinal axis position (upper, middle or lower third of the stomach), cross-sectional position (anterior gastric wall, posterior gastric wall, lesser curvature or greater curvature), gross type of EGC, lesion diameter $(\mathrm{cm})$, diameter of the resected specimen $(\mathrm{cm})$, histological type (differentiation degree), ESD time, bleeding condition under emergency endoscopy (pulsatile bleeding, active permeating bleeding, vessel exposure, bloodstain or blood clot) and post-operative blood transfusion. The rates of delayed bleeding with and without SLE were used as the endpoints to determine the effectiveness of SLE.

Statistical analysis. SPSS 18.0 (SPSS, Inc., Chicago, IL, USA) was used for statistical analysis. The Student's t-test or Fisher's exact test was used to analyze differences in patient age, tumor size, specimen size and ESD operative time between the two groups. The chi-square test was used to analyze differences in sex, complications, use of anti-coagulation or anti-platelet drugs, longitudinal axis position, cross-sectional position, gross type and degree of differentiation. If more than one predictive index was significantly different on the Cox proportional hazards model was used to determine the independent risk factors. Optimum cut-off values for risk factors were determined using receiver operating characteristic analysis. A two-sided $\mathrm{P}<0.05$ was considered to indicate a statistically significant difference.

\section{Results}

Characteristics of the surgeries. Fig. 1 presents the patient flow chart. Table I presents the characteristics of the 2 groups at baseline. The en bloc resection rate was $100 \%$. All resection margins were negative. No gastrointestinal perforation, death or severe complication occurred. The median time interval between ESD and SLE was 2 days after surgery (range, 1-3 days). For patients in the SLE group $(n=110)$ and the
non-SLE group $(n=100)$, the mean operative time was $69 \pm 38$ and $89 \pm 35 \mathrm{~min}$, the mean lesion diameter was $2.8 \pm 0.9$ and $2.5 \pm 1.2 \mathrm{~cm}$ and the number of specimens sized $>40 \mathrm{~mm}$ was 8 and 10, respectively. There were no significant differences between the 2 groups with regard to the abovementioned parameters $(\mathrm{P}>0.05)$. Late delayed bleeding was observed 2 days following ESD in the non-SLE group. The incidence of late delayed bleeding occurring after SLE was significantly different (4.5 vs. $12.0 \%$, respectively; $\mathrm{P}<0.05$; Table I). Table I also provides information on the occurrence of late delayed bleeding.

Early delayed bleeding. Among the 210 patients, 20 (9.5\%) demonstrated early delayed bleeding following ESD. However, no statistically significant differences were identified between patients with SLE and non-SLE groups $(P>0.05)$. The flat gross type $(\mathrm{P}<0.01)$, ulcer $(\mathrm{P}<0.01)$ and specimen size $>40 \mathrm{~mm}$ (4.6 vs. $30 \%$; $\mathrm{P}<0.001$ ) was associated with an increased risk of early delayed bleeding. Furthermore, artificial ulcer diameter $(2.61 \pm 1.20$ vs. $4.06 \pm 1.73 \mathrm{~cm} ; \mathrm{P}<0.001)$ was associated with significantly higher early delayed bleeding rates (Table II). Univariate analysis (Table III) revealed that early delayed bleeding was associated with ulcer, flat gross type, artificial ulcer diameter $(>3 \mathrm{~cm})$ and the resected tumor size $(>40 \mathrm{~mm})$. Multivariate analysis (Table IV) revealed that the flat gross type $(\mathrm{OR}=16.315$; $95 \%$ CI: 2.874-92.625; $\mathrm{P}<0.01)$, ulcer $(\mathrm{OR}=1.052$; 95\% CI: $1.011-1.094 ; \mathrm{P}<0.05)$, the resected tumor size $>40 \mathrm{~mm}$ $(\mathrm{OR}=1.189 ; 95 \% \mathrm{CI}: 1.111-1.272 ; \mathrm{P}<0.01)$ and artificial ulcer diameter ( $>3 \mathrm{~cm}$; OR=1.226; 95\% CI: 1.118-1.345; $\mathrm{P}<0.001$ ) were independently associated with early delayed bleeding.

Late delayed bleeding. Among the 210 patients, 17 (8.1\%) had late delayed bleeding after ESD and statistically significant differences were identified between the patients with and without SLE $(\mathrm{P}<0.05)$. The median interval between bleeding and ESD among these 17 patients was 1 day (range, 1-10 days) and operation time (61.57 \pm 18.58 vs. $78.82 \pm 24.40 \mathrm{~min} \mathrm{P}=0.001)$ increased the risk of late delayed bleeding (Table V). Bleeding was successfully stopped in all patients during SLE and none of the patients required 
Table I. Characteristics of patients with delayed bleeding after gastric endoscopic submucosal dissection in the SLE and non-SLE groups.

\begin{tabular}{|c|c|c|c|}
\hline Characteristic & SLE group $(n=110)$ & Non-SLE group $(n=100)$ & P-value \\
\hline Age (years, mean \pm SD) & $61.5 \pm 10.6$ & $65.5 \pm 10.2$ & 0.557 \\
\hline Male sex & $83(75.5)$ & $71(71.0)$ & 0.283 \\
\hline \multicolumn{4}{|l|}{ Location of lesion } \\
\hline Upper third & $28(25.5)$ & $18(18.0)$ & 0.192 \\
\hline Middle third & $32(29.0)$ & $36(36.0)$ & 0.285 \\
\hline Lower third & $50(45.5)$ & $46(46.0)$ & 0.937 \\
\hline \multicolumn{4}{|l|}{ Gross type } \\
\hline Elevated & $57(51.8)$ & $56(56.0)$ & 0.544 \\
\hline Flat & $12(10.9)$ & $9(9.0)$ & 0.645 \\
\hline Depressed & $41(37.3)$ & $35(35.0)$ & 0.732 \\
\hline \multicolumn{4}{|l|}{ Ulcer } \\
\hline Surface redness & $73(66.4)$ & $66(66.0)$ & 0.956 \\
\hline Surface erosion & $21(19.1)$ & $23(23.0)$ & 0.487 \\
\hline Submucosal fibrosis & $16(14.5)$ & $11(11.0)$ & 0.443 \\
\hline \multicolumn{4}{|l|}{ Degree of differentiation } \\
\hline Well-differentiated carcinoma & $90(81.8)$ & $82(82.0)$ & 0.973 \\
\hline Poorly differentiated carcinoma & $20(18.2)$ & $18(18.0)$ & \\
\hline Lesion diameter $(\mathrm{cm}$, mean $\pm \mathrm{SD})$ & $2.8 \pm 0.9$ & $2.5 \pm 1.2$ & 0.178 \\
\hline Artificial ulcer diameter $(\mathrm{cm}$, mean \pm SD $)$ & $4.0 \pm 1.3$ & $2.6 \pm 1.2$ & 0.954 \\
\hline Helicobacter pylori infection & $96(87.3)$ & $81(81.0)$ & 0.256 \\
\hline Abdominal pain & $40(36.4)$ & $31(31.0)$ & 0.412 \\
\hline Early delayed bleeding & $12(10.9)$ & $8(8.0)$ & 0.316 \\
\hline Late delayed bleeding & $5(4.5)$ & $12(12.0)$ & 0.028 \\
\hline Operation time $(\min$, mean $\pm \mathrm{SD})$ & $69.4 \pm 38.2$ & $89.3 \pm 34.7$ & 0.130 \\
\hline Specimens sized $>40 \mathrm{~mm}$ & $8(7.2)$ & $10(10.0)$ & 0.323 \\
\hline
\end{tabular}

Values are expressed as the mean \pm SD unless otherwise indicated or n (\%). SLE, second-look endoscopy.

re-operation. No re-bleeding occurred during the follow-up in the 173 patients without delayed bleeding. Among the 17 patients with delayed bleeding, 2 (11.8\%) required blood transfusion.

Seventeen cases of late delayed bleeding were divided into 3 types: Pulsatile bleeding ( $n=8$; Forrest grade I), active permeating bleeding ( $n=6$; Forrest grade IIa) and vessel exposure ( $n=3$; Forrest grade IIb). One patient underwent SLE on the second day after ESD, but delayed bleeding occurred on the tenth day after ESD. The patient had a remnant stomach with the lesion located on the anterior wall of the gastric antrum, and the size of the excised lesion was $1.5 \times 1.5 \mathrm{~cm}$.

Univariate analysis (Table VI) revealed that late delayed bleeding was associated with male sex, ulcer, flat gross type, lesion diameter $(>2 \mathrm{~cm})$, specimen size of $>40 \mathrm{~mm}$, longer operative time ( $>60 \mathrm{~min} ; 61.57 \pm 18.58$ vs. $78.82 \pm 24.40 \mathrm{~min}$; $\mathrm{P}<0.01$ ) and $H$. pylori infection (86.1 vs. $58.8 \% ; \mathrm{P}<0.01$ ). Multivariate analysis (Table VII) revealed that ulcer [odds ratio $(\mathrm{OR})=3.752,95 \%$ confidence interval $(\mathrm{CI}): 3.202-7.052, \mathrm{P}<0.05]$, flat gross type $(\mathrm{OR}=4.229,95 \% \mathrm{CI}: 1.355-14.258, \mathrm{P}<0.05)$, lesion diameter $(\mathrm{OR}=1.470,95 \% \mathrm{CI}: 1.047-2.064, \mathrm{P}<0.05)$, specimen size of $>40 \mathrm{~mm}(\mathrm{OR}=1.139,95 \%$ CI: $0.988-1.314, \mathrm{P}<0.01)$ and $H$. pylori infection $(\mathrm{OR}=1.112,95 \% \mathrm{CI}$ : $0.309-1.225, \mathrm{P}<0.01)$ were independently associated with the occurrence of late delayed bleeding.

\section{Discussion}

It is controversial whether SLE is able to prevent delayed bleeding after ESD for gastric cancer. Therefore, the present study aimed to evaluate whether SLE is able to prevent delayed bleeding after ESD and clarified the types of lesions that require SLE. The results suggest that SLE was effective in preventing delayed bleeding after ESD, particularly within $48 \mathrm{~h}$ after ESD. Lesion diameter $(>2 \mathrm{~cm})$, ulcer, flat gross type, the resected tumor $>40 \mathrm{~mm}, H$. pylori infection and operative time ( $>60 \mathrm{~min}$ ) were independently associated with late delayed bleeding after ESD, while flat gross type, ulcer, the resected tumor $>40 \mathrm{~mm}$ and artificial ulcer diameter $(>3 \mathrm{~cm})$ were independently associated with early delayed bleeding.

Certain studies have indicated that procedure-associated bleeding is not associated with age, sex, tumor size and tumor location (21). In addition, the preventive coagulation of non-bleeding visible vessels in SLE following gastric ESD may do little to prevent late delayed bleeding (20), SLE for preventing delayed bleeding after ESD may be 
Table II. Analysis of risk factors related to early delayed bleeding.

\begin{tabular}{|c|c|c|c|}
\hline Variable & No bleeding $(N=173)$ & Early delayed bleeding $(N=20)$ & P-value \\
\hline Age (years, mean \pm SD) & $57.9 \pm 9.5$ & $61.7 \pm 10.1$ & 0.290 \\
\hline Male sex & $120(69.4)$ & $18(90.0)$ & 0.066 \\
\hline Location & & & 0.571 \\
\hline Upper $1 / 3$ & $35(20.3)$ & $6(30.0)$ & \\
\hline Middle 1/3 & $62(35.8)$ & $2(10.0)$ & \\
\hline Lower $1 / 3$ & $76(43.9)$ & $12(60.0)$ & \\
\hline Ulcer & $18(10.4)$ & $7(35.0)$ & 0.007 \\
\hline Gross type & & & 0.030 \\
\hline Elevated & $98(56.6)$ & $5(25.0)$ & \\
\hline Flat & $12(6.9)$ & $6(30.0)$ & \\
\hline Depressed & $63(36.4)$ & $9(45.0)$ & \\
\hline Lesion diameter $(\mathrm{cm}$, mean $\pm \mathrm{SD})$ & $2.29 \pm 1.24$ & $3.61 \pm 1.43$ & 0.221 \\
\hline Artificial ulcer diameter $(\mathrm{cm}$, mean $\pm \mathrm{SD})$ & $2.61 \pm 1.20$ & $4.06 \pm 1.73$ & 0.000 \\
\hline The resected tumor of $>40 \mathrm{~mm}$ & $8(4.6)$ & $6(30.0)$ & 0.000 \\
\hline Operation time (min, mean $\pm \mathrm{SD})$ & $61.57 \pm 18.58$ & $78.82 \pm 24.40$ & 0.240 \\
\hline Pathology & & & 0.537 \\
\hline Well-differentiated carcinoma & $141(81.5)$ & $18(90.0)$ & \\
\hline Poorly differentiated carcinoma & $32(18.5)$ & $2(10.0)$ & \\
\hline Depth of invasion & & & 0.787 \\
\hline Mucous layer & $64(37.0)$ & $4(20.0)$ & \\
\hline Mucosal muscular layer & $99(57.2)$ & $11(55.0)$ & \\
\hline Submucosa layer & $10(5.8)$ & $5(25.0)$ & \\
\hline Helicobacter pylori infection & $149(86.1)$ & $18(90.0)$ & 0.631 \\
\hline
\end{tabular}

Table III. Univariate analysis of factors associated with early delayed bleeding after endoscopic submucosal dissection.

\begin{tabular}{lll}
\hline Variable & OR $(95 \%$ CI $)$ & P-value \\
\hline Age $(>60$ vs. $\leq 60$ years) & $0.993(0.957-1.030)$ & 0.698 \\
Sex (male vs. female) & $4.038(0.903-18.065)$ & 0.068 \\
Location of lesion (upper third vs. other locations) & $0.394(0.050-3.134)$ & 0.379 \\
Ulcer (yes vs. no) & $4.631(1.592-13.476)$ & 0.005 \\
Gross type (flat gross type vs. other types) & $8.500(1.856-38.938)$ & 0.006 \\
Lesion diameter $(>2$ vs. $\leq 2 \mathrm{~cm})$ & $0.973(0.878-1.079)$ & 0.607 \\
Artificial ulcer diameter $(>3$ vs. $\leq 3 \mathrm{~cm})$ & $1.123(1.020-1.237)$ \\
The resected tumor size $(>40$ vs. $\leq 40$ mm) & $8.455(2.553-27.998)$ \\
Operation time $(>60$ vs. $\leq 60$ min) & $1.018(0.991-1.045)$ & 0.019 \\
Degree of differentiation (poorly. vs. well differentiated carcinoma) & $0.272(0.056-1.328)$ \\
Depth of infiltration (mucous layer vs. all others) & $0.321(0.089-1.163)$ & 0.190 \\
Helicobacter pylori infection (yes vs. no) & $1.008(0.210-4.835)$
\end{tabular}

CI, confidence interval; OR, odds ratio.

excessively performed at present and unnecessary in certain patients $(16,18,19)$. However, the present study suggested that SLE has an important role after gastric ESD, as it is able to identify and treat potential bleeding foci. Takizawa et al (23) suggested that coagulation of visible vessels during ESD prevented delayed bleeding. Therefore, different approaches may be used to prevent bleeding and avoid a second endoscopy.
In the present study, the lesions were completely excised during ESD in all 210 patients who met the criteria for SLE after ESD. The results indicated that late delayed bleeding was markedly more common in the non-SLE group, and numerous patients had $H$. pylori infection, which may cause a greater local inflammatory response and further influence the gastric mucosal blood flow during healing of 
Table IV. Multivariate analysis of factors associated with early delayed bleeding after endoscopic submucosal dissection.

\begin{tabular}{lrr}
\hline Parameter & OR (95\% CI) & P-value \\
\hline Flat gross type (flat gross vs all other gross types) & $16.315(2.874-92.625)$ & 0.002 \\
Ulcer (yes vs. no) & $1.052(1.011-1.094)$ & 0.012 \\
The resected tumor size $(>40$ vs. $\leq 40 \mathrm{~mm})$ & $1.189(1.111-1.272)$ & 0.007 \\
Artificial ulcer diameter $(>3 \mathrm{vs} . \leq 3 \mathrm{~cm})$ & $1.226(1.118-1.345)$ & $<0.001$ \\
\hline
\end{tabular}

CI, confidence interval; OR, odds ratio.

Table V. Analysis of risk factors related to late delayed bleeding.

\begin{tabular}{|c|c|c|c|}
\hline Variable & No bleeding $(N=173)$ & Late delayed bleeding $(N=17)$ & P-value \\
\hline Age (years, mean \pm SD) & $57.9 \pm 9.5$ & $57.1 \pm 10.6$ & 0.740 \\
\hline Male sex & $120(69.4)$ & $16(94.1)$ & 0.045 \\
\hline Location & & & 0.119 \\
\hline Upper $1 / 3$ & $35(20.3)$ & $5(29.4)$ & \\
\hline Middle $1 / 3$ & $62(35.8)$ & $4(23.5)$ & \\
\hline Lower $1 / 3$ & $76(43.9)$ & $8(47.1)$ & \\
\hline Ulcer & $18(10.4)$ & $8(47.1)$ & 0.000 \\
\hline Gross type & & & 0.011 \\
\hline Elevated & $98(56.6)$ & $10(58.8)$ & \\
\hline Flat & $12(6.9)$ & $3(17.6)$ & \\
\hline Depressed & $63(36.4)$ & $4(23.5)$ & \\
\hline Lesion diameter $(\mathrm{cm}$, mean $\pm \mathrm{SD})$ & $2.29 \pm 1.24$ & $3.61 \pm 1.43$ & 0.006 \\
\hline Artificial ulcer diameter $(\mathrm{cm}$, mean $\pm \mathrm{SD})$ & $2.61 \pm 1.20$ & $4.06 \pm 1.73$ & 0.595 \\
\hline The resected tumor of $>40 \mathrm{~mm}$ & $8(4.6)$ & $4(23.5)$ & 0.014 \\
\hline Operation time (min, mean $\pm \mathrm{SD}$ ) & $61.57 \pm 18.58$ & $78.82 \pm 24.40$ & 0.001 \\
\hline Pathology & & & 0.535 \\
\hline Well-differentiated carcinoma & $141(81.5)$ & $13(76.5)$ & \\
\hline Poorly differentiated carcinoma & $32(18.5)$ & $4(23.5)$ & \\
\hline Depth of invasion & & & 0.182 \\
\hline Mucous layer & $64(37.0)$ & $3(17.6)$ & \\
\hline Mucosal muscular layer & $99(57.2)$ & $8(47.1)$ & \\
\hline Submucosa layer & $10(5.8)$ & $6(35.3)$ & \\
\hline Helicobacter pylori infection & $149(86.1)$ & $10(58.8)$ & 0.009 \\
\hline
\end{tabular}

ESD-induced ulcer, resulting in injury to the vessel walls. Flat gross type is another risk factor; as such lesions are frequently rich in vascularity and are mostly reddish due to the existence of more vessels in the submucosal layer compared with that in the elevated or depressed type. The presence of more vessels may increase the risk of post-ESD bleeding (11). There was no significant association between age and ESD-associated hemorrhage, which was inconsistent with the results reported by Takahashi et al (18). Regarding the post-operative complications of ESD, the rates of perforation, bleeding, and lymphatic vessel invasion were lower than those reported in previous studies (11,14,16-20,24-26), which may be due to the improvements in therapeutic instruments and techniques, as well as the absence of positive margins in the 210 patients.
Certain studies have examined the risk factors for delayed bleeding after ESD. Choi et al (24) determined that surface erosion, location of the lesion and high-risk ulcer were independently associated with the risk of delayed bleeding. In a study by Kim et al (16), a large tumor size (>20 mm) was the only independent risk factor for delayed bleeding. Nakamura et al (27) reported that low platelets and positive lateral margins were associated with delayed bleeding. Other risk factors include wide resection $(14,18,22)$, no post-ESD coagulation (23), tumor located in the lower third of the stomach $(22,23)$, tumor located in the L segment (18), large tumor size (18), histological ulcer (14), long ESD procedure (14), age of $<65$ years (26) and use of anti-thrombotic drugs (26). Ryu et al (19) reported that no specific factor was associated with delayed bleeding after ESD. In the present study, ulcer, 
Table VI. Univariate analysis of the association of various clinicopathological and surgical parameters with the incidence of late delayed bleeding after endoscopic submucosal dissection.

\begin{tabular}{llr}
\hline Variable & \multicolumn{1}{c}{ OR (95\% CI) } & P-value \\
\hline Age (>60 vs. $\leq 60$ years) & $0.963(0.910-1.019)$ & 0.189 \\
Sex (male vs. female) & $8.210(1.055-63.869)$ & 0.044 \\
Location of lesion (upper third vs. other locations) & $1.676(0.446-6.302)$ & 0.445 \\
Ulcer (yes vs. no) & $6.791(1.963-23.496)$ & 0.002 \\
Gross type (flat gross type vs. other types) & $6.012(1.338-27.006)$ & 0.019 \\
Lesion diameter $(>2$ vs. $\leq 2 \mathrm{~cm})$ & $1.174(1.064-1.295)$ & 0.001 \\
Artificial ulcer diameter $(>3$ vs. $\leq 3 \mathrm{~cm})$ & $0.992(0.933-1.055)$ & 0.800 \\
The resected tumor size (>40 vs. $\leq 40$ mm) & $8.040(2.003-32.273)$ & 0.003 \\
Operation time $(>60$ vs. $\leq 60$ min) & $1.034(1.010-1.058)$ & 0.005 \\
Degree of differentiation (poorly vs. well differentiated) & $1.023(0.261-4.006)$ & 0.973 \\
Depth of infiltration $($ mucous layer vs. all others) & $0.343(0.075-1.570)$ & 0.168 \\
Helicobacter pylori infection (yes vs. no) & $0.022(0.003-0.182)$ & $<0.001$
\end{tabular}

CI, confidence interval; OR, odds ratio.

Table VII. Multivariate analysis of factors associated with late delayed bleeding after endoscopic submucosal dissection.

\begin{tabular}{llr}
\hline Parameter & OR (95\% CI) & P-value \\
\hline Sex (male vs. female) & $0.007(0.202-3.013)$ & 0.775 \\
Ulcer (yes vs. no) & $3.752(3.202-7.052)$ & 0.031 \\
Flat gross type (vs. all other gross types) & $4.229(1.355-14.258)$ & 0.013 \\
Lesion diameter (>2 vs. $\leq 2 \mathrm{~cm})$ & $1.470(1.047-2.064)$ & 0.026 \\
Operation time (>60 vs. $\leq 60 \mathrm{~min})$ & $1.099(0.976-1.238)$ & 0.119 \\
The resected tumor size (>40 vs. $\leq 40 \mathrm{~mm})$ & $1.139(0.988-1.314)$ & 0.002 \\
Helicobacter pylori infection (yes vs. no) & $1.112(0.309-1.225)$ & 0.002 \\
\hline
\end{tabular}

CI, confidence interval; OR, odds ratio.

flat gross type, lesion diameter $(>2 \mathrm{~cm})$, the resected tumor size of $>40 \mathrm{~mm}$ and $H$. pylori infection were independently associated with late delayed bleeding after ESD, while flat gross type, ulcer, the resected tumor size of $>40 \mathrm{~mm}$ and artificial ulcer diameter $(>3 \mathrm{~cm})$ were independently associated with early delayed bleeding. Of note, the present study is not without limitations. It was a retrospective study, with all of the inherent limitations, and the sample size was small.

In conclusion, based on the present retrospective study, SLE after ESD has a certain value in the prevention of delayed bleeding in patients with gastric cancer after treatment with ESD, particularly within $48 \mathrm{~h}$ after the surgery. Ulcer, flat gross type, lesion diameter $(>2 \mathrm{~cm})$, the resected tumor size of $>40 \mathrm{~mm}$ and $H$. pylori infection were used to identify those high-risk patients who should ideally be subjected to SLE to prevent late delayed bleeding.

\section{Acknowledgements}

Part of the data of the present study has been presented as a poster at the 17th Congress of Gastroenterology China, (Xi'an, China), 14-16 September 2017 (28).

\section{Funding}

No funding received.

\section{Availability of data and materials}

The datasets used and/or analyzed during the current study are available from the corresponding author on reasonable request.

\section{Authors' contributions}

ZG wrote the manuscript. LM and $\mathrm{HH}$ contributed to project development and data collection. LC and $\mathrm{ZG}$ recorded and analyzed the results. LC and YX performed the statistical analysis. All authors have read and approved the final manuscript.

\section{Ethics approval and consent to participate}

The present study was approved by the ethics committee of the Second Affiliated Hospital of Nanjing Medical University and 
Qilu Hospital of Shandong University. All patients provided written informed consent for inclusion in the database.

\section{Patient consent for publication}

Not applicable.

\section{Competing interests}

The authors declare that they have no competing interests.

\section{References}

1. Thrumurthy SG, Chaudry MA, Hochhauser D and Mughal M: The diagnosis and management of gastric cancer. BMJ 347: f6367, 2013.

2. Kohler BA, Ward E, McCarthy BJ, Schymura MJ, Ries LA, Eheman C, Jemal A, Anderson RN, Ajani UA and Edwards BK Annual report to the nation on the status of cancer, 1975-2007, featuring tumors of the brain and other nervous system. J Natl Cancer Inst 103: 714-736, 2011.

3. Yang L: Incidence and mortality of gastric cancer in China. World J Gastroenterol 12: 17-20, 2006.

4. Salih BA: Helicobacter pylori infection in developing countries: The burden for how long? Saudi J Gastroenterol 15: 201-207, 2009.

5. NCCN Clinical Practice Guidelines in Oncology (NCCN Guidelines). Gastric Cancer. Version 2.2017. National Comprehensive Cancer Network, Fort Washington, 2017.

6. Wang S, Zhang Z, Liu M, Li S and Jiang C: Endoscopic resection compared with gastrectomy to treat early gastric cancer: A systematic review and meta-analysis. PLoS One 10: e0144774, 2015.

7. Ono H, Yao K, Fujishiro M, Oda I, Nimura S, Yahagi N, Iishi H, Oka M, Ajioka Y, Ichinose M and Matsui T: Guidelines for endoscopic submucosal dissection and endoscopic mucosal resection for early gastric cancer. Dig Endosc 28: 3-15, 2016.

8. Inoue H, Ikeda H, Hosoya T, Yoshida A, Onimaru M, Suzuki M and Kudo SE: Endoscopic mucosal resection, endoscopic submucosal dissection, and beyond: Full-layer resection for gastric cancer with nonexposure technique (CLEAN-NET). Surg Oncol Clin N Am 21: 129-140, 2012.

9. Facciorusso A, Antonino M, Di Maso M and Muscatiello N: Endoscopic submucosal dissection vs endoscopic mucosal resection for early gastric cancer: A meta-analysis. World J Gastrointest Endose 6: 555-563, 2014.

10. Park CH, Shin S, Park JC, Shin SK, Lee SK, Lee YC and Lee H: Long-term outcome of early gastric cancer after endoscopic submucosal dissection: Expanded indication is comparable to absolute indication. Dig Liver Dis 45: 651-656, 2013.

11. Goto O, Fujishiro M, Kodashima S, Ono S, Niimi K, Hirano K, Yamamichi N and Koike K: A second-look endoscopy after endoscopic submucosal dissection for gastric epithelial neoplasm may be unnecessary: A retrospective analysis of postendoscopic submucosal dissection bleeding. Gastrointest Endosc 71: 241-248, 2010

12. Kataoka Y, Tsuji Y, Sakaguchi Y, Minatsuki C, Asada-Hirayama I, Niimi K, Ono S, Kodashima S, Yamamichi N, Fujishiro M and Koike K: Bleeding after endoscopic submucosal dissection: Risk factors and preventive methods. World J Gastroenterol 22: 5927-5935, 2016

13. Kang KJ, Kim KM, Min BH, Lee JH and Kim JJ: Endoscopic submucosal dissection of early gastric cancer. Gut Liver 5: 418-426, 2011.

14. Ono S, Ono M, Nakagawa M, Shimizu $Y$, Kato $M$ and Sakamoto N: Delayed bleeding and hemorrhage of mucosal defects after gastric endoscopic submucosal dissection on second-look endoscopy. Gastric Cancer 19: 561-567, 2016.
15. Akintoye E, Obaitan I, Muthusamy A, Akanbi O, Olusunmade M and Levine D: Endoscopic submucosal dissection of gastric tumors: A systematic review and meta-analysis. World J Gastrointest Endosc 8: 517-532, 2016.

16. Kim JS, Chung MW, Chung CY, Park HC, Ryang DY, Myung DS, Cho SB, Lee WS and Joo YE: The need for second-look endoscopy to prevent delayed bleeding after endoscopic submucosal dissection for gastric neoplasms: A prospective randomized trial. Gut Liver 8: 480-486, 2014.

17. MochizukiS,UedoN,OdaI,KanekoK, Yamamoto Y, YamashinaT, Suzuki H, Kodashima S, Yano T, Yamamichi N, et al: Scheduled second-look endoscopy is not recommended after endoscopic submucosal dissection for gastric neoplasms (the SAFE trial): A multicentre prospective randomised controlled non-inferiority trial. Gut 64: 397-405, 2015.

18. Takahashi F, Yoshitake N, Akima T, Kino H, Nakano M, Tsuchida C, Tsuchida K, Tominaga K, Sasai T, Masuyama H and Hiraishi H: A second-look endoscopy may not reduce the bleeding after endoscopic submucosal dissection for gastric epithelial neoplasm. BMC Gastroenterol 14: 152, 2014.

19. Ryu HY, Kim JW, Kim HS, Park HJ, Jeon HK, Park SY, Kim BR, Lang CC and Won SH: Second-look endoscopy is not associated with better clinical outcomes after gastric endoscopic submucosal dissection: A prospective, randomized, clinical trial analyzed on an as-treated basis. Gastrointestl Endosc 78: 285-294, 2013.

20. Na S, Ahn JY, Choi KD, Kim MY, Lee JH, Choi KS, Kim DH, Song HJ, Lee GH, Jung HY and Kim JH: Delayed bleeding rate according to the Forrest classification in second-look endoscopy after endoscopic submucosal dissection. Dig Dis Sci 60: 3108-3117, 2015.

21. Isomoto H, Shikuwa S, Yamaguchi N, Fukuda E, Ikeda K, Nishiyama H, Ohnita K, Mizuta Y, Shiozawa J and Kohno S: Endoscopic submucosal dissection for early gastric cancer: A large-scale feasibility study. Gut 58: 331-336, 2009

22. Okada K, Yamamoto Y, Kasuga A, Omae M, Kubota M, Hirasawa T, Ishiyama A, Chino A, Tsuchida T, Fujisaki J, et al: Risk factors for delayed bleeding after endoscopic submucosal dissection for gastric neoplasm. Surg Endosc 25: 98-107, 2011.

23. Takizawa K, Oda I, Gotoda T, Yokoi C, Matsuda T, Saito Y, Saito D and Ono H: Routine coagulation of visible vessels may prevent delayed bleeding after endoscopic submucosal dissection-an analysis of risk factors. Endoscopy 40: 179-183, 2008.

24. Choi CW, Kim HW, Kang DH, Hong YM, Kim SJ, Park SB, Cho M, Kim DJ and Hong JB: Clinical outcomes of second-look endoscopy after gastric endoscopic submucosal dissection: Predictive factors with high risks of bleeding. Surg Endosc 28: 2213-2220, 2014.

25. Fujishiro M, Abe N, Endo M, Kawahara Y, Shimoda R, Nagata S, Homma K, Morita Y and Uedo N: Current managements and outcomes of peptic and artificial ulcer bleeding in Japan. Dig Endosc 22 (Suppl 1): S9-S14, 2010

26. Tano S, Horiki N, Omata F, Tanaka K, Hamada Y, Katsurahara M, Ninomiya K, Nishikawa K, Nojiri K, Yamada R, et al: Second and third-look endoscopy for the prevention of post-ESD bleeding. Medicine (Baltimore) 94: e491, 2015.

27. Nakamura M, Nishikawa J, Hamabe K, Nishimura J, Satake M, Goto A, Kiyotoki S, Saito M, Fukagawa Y, Shirai Y, et al: Risk factors for delayed bleeding from endoscopic submucosal dissection of gastric neoplasms. Scand J Gastroenterol 47: 1108-1114, 2012.

28. Guo Z, Xin Y, Dai H and Cao J: Second-look endoscopy could be effective in preventing delayed bleeding after gastric endoscopic submucosal dissection. Abstract No: PO-937. In: The 17th Congress of Gastroenterology China (CGC), 2017.

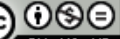

This work is licensed under a Creative Commons Attribution-NonCommercial-NoDerivatives 4.0 International (CC BY-NC-ND 4.0) License. 